\title{
PEDAGOGICAL INTERACTIONS IN PRIMARY SCHOOL REINTEGRATION PROCESSES: A CASE STUDY IN CHILE
}

\author{
José Manuel Medina, Tatiana Herreros, Pamela De Barca, \& Carolina Crovetto \\ Facultad de Educación, Universidad de Las Américas (Chile)
}

\begin{abstract}
In Chile, despite the great coverage achieved, there are still children and adolescents who leave school without being able to complete 12 years of compulsory education (Casen, 2015); moreover, among the countries that make up the OECD, Chile is in the first places of deschooling (TALIS, 2013). This marginalization from the school system is affecting a significant number of children and hindering areas of integration and social development, which accentuates processes of social exclusion and violation of rights in Chile (Casen, 2015; Mide-UC, 2016; Mineduc, 2017). This is reinforced by pedagogical practices that strengthen these probabilities of failure (Román, 2013).

The phenomenon of school reintegration has little evidence in relation to the human and technical component in school reintegration processes, either locally (Mide-UC, 2016; UNESCO-UNICEF-Chilean Association of Municipalities, 2012), or internationally (CEPAL, 2010; Contreras et al, 2014; Sucre, 2016), which implies observing and analyzing pedagogical intervention practices in these contexts, in terms of how these dialogical-reflective relational dynamics between teachers and children and adolescents are developed, from the perspective of pedagogical interactions, an area of growing interest in educational sciences, which looks at more than the action itself, at how and what happens in the interaction. (Colomina et al, 2001)

This research from a qualitative, transactional approach, oriented from the perspective of descriptive studies (Hernández,et al, 2010) and enriched with the symbolic interactionism of Blumer (1969), whose contributions indicate that the nature of the teaching-learning processes can only be unraveled through direct examination, seeks to understand pedagogical intervention practices from the perspective of pedagogical interactions which are developed between teachers and their students, within the framework of the specialized protection programs in school reintegration implemented in Chile by the National Service for Minors of the Ministry of Justice and Human Rights, in vulnerable sectors of the communes of Talca, Region of Maule and La Pintana, Metropolitan Region.

The analysis through the theoretical and empirical contributions provided by the scientific evidence on pedagogical interactions, in terms of how they are configured, deployed and how these pedagogical intervention practices are perceived by the actors involved, added to the findings obtained, provides an opportunity to innovate by allowing the observation of school reintegration as a scenario of human relations and to deepen around this professional action as a critical element, constituting the improvement of teaching and effectiveness in school reintegration processes.
\end{abstract}

Keywords: School reintegration, educational interaction, learning, teacher, students.

\section{Formulation of the study}

This project is part of the field of education and school reintegration, with a focus on the educational interactions that take place in the pedagogical interventions between teachers and children and adolescents assigned to the Specialized Protection Programs in Educational Reinsertion in different communes of Chili.

There is proven national and international evidence regarding children and adolescents who are outside the school system or show indicators of educational fragility, which represents a clear situation of violation of rights. In this regard, in the international context, the evidence shows that in Latin America approximately 3 million of the child population are outside the school system, which is equivalent to $6.1 \%$ (UNICEF, 2012b) and in secondary education, in its phase early childhood (between 11 and 15 years old), $7.6 \%$ of adolescents, that is, 3 million, are out of school (UNESCO, 2014). In Chile, the CASEN survey (2015) indicates that, despite the high coverage achieved, there are still boys, girls and 
adolescents who drop out of school without being able to complete 12 years of compulsory education. Moreover, among the countries that make up the OECD, Chile is in the first places in out-of-schooling in secondary education (TALIS, 2013).

In response to this need to guarantee a successful school career for Chilean children and adolescents, in 2010 the Specialized Protection Program in Educational Reintegration (hereinafter PDE) was born, basing its main argument on a rights approach where access to both basic and secondary education constitute a right formally guaranteed by the State of Chile.

Today, reintegration projects face complex processes that pursue, through resignification, a transformation of the learning experience (SENAME, 2017), since the abandonment of the school system is due, among other causes, to inadequate experiences from what pedagogical (Román, 2013). The responsibility of resignifying the learning experience requires that these projects tend towards an ecological intervention model where the progressive mutual accommodation between a human being in the process of development and the changing properties of the immediate environments (Bronfenbrenner, 1987), are conditioned by means of Intervention practices that ensure a correct acquisition or strengthening of knowledge and the development of psychosocial skills so that children and adolescents can be conceived as a subject with learning capacity (MIDE UC, 2016).

Studies on the effectiveness of school reintegration plans in Latin America and Chile, carried out through the analysis of intervention programs (ECLAC, 2010; Contreras et al, 2014; Sucre, 2016), or reinsertion trajectories (MIDE UC, 2016), show evidence that supports the need to observe and analyze pedagogical intervention practices in contexts of school reintegration (UNESCO-UNICEF-Chilean Association of Municipalities, 2012).

In this regard, research on interaction, a field of growing research interest in science (Colomina et al, 2001) makes sense in processes of school reintegration, as it emerges as a contribution to the understanding of human relationships in specific contexts. This represents a dialogical and didactic challenge for the education professional who tries to maintain constant communication with the student, linked to multiple relationship channels (Schütz, 1993) and which also empowers him to recognize progress states supported by performance evidence and student performance in pedagogical intervention processes.

Analyzing the intervention practices in execution in the framework of these school reintegration programs from the voice of the education professionals involved, provides an opportunity to observe the intervention practice from its configuration as a scene of human relations and deepen around this Professional action as a critical element, constitutive of effectiveness in school reintegration. Therefore, the research question is: What meaning do the education professionals linked to these school reintegration programs attribute to the educational interactions between teachers and students during the pedagogical intervention processes?

\section{Methodology}

The design is theoretical-methodological, being a non-experimental investigation with a qualitative, transactional approach, oriented from the perspective of descriptive studies (Hernández and others, 2010) and enriched with the symbolic interactionism of Blumer (1969).

Grounded Theory will be used through the method of constant comparisons (Glaser and Strauss, 1967). This is a generative and constructive method in which the inductive coding of categories is combined with the constant comparison between them. It seeks the dynamic construction of meanings, focusing on temporal patterns of meaning, enabling intra and intersubjective analysis of perceptions and meanings. It starts from the sociolinguistic premise that the construction of meanings strongly depends on the various forms that the combination of contents and meanings takes during the flow of discourse.

Regarding the selection of informants, this study assumes an intentional non-probabilistic sampling for the selection of informants (Taylor and Bogdan, 1987; Hernández and others, 2010). It is planned to have the participation of 16 teachers belonging to the Specialized Protection Programs in Educational Reintegration from different communes of the country.

Regarding the instruments for collecting information, it is intended to respond to the specific objectives through the use of in-depth interviews to recall the memory (Erickson and Simon, 1993).

\section{Discussion and preliminary conclusions of an ongoing investigation}

Favoring the conditions and strengthening the educational trajectory of children and adolescents who are out of school or present educational fragility is established as an effective response, through school reintegration programs, to this country responsibility, where education should be within everyone's reach. However, the marginalization of the school system seen from school dropout is an undeniable fact 
(CASEN, 2015; MIDE UC, 2016) affecting a large number of minors, preventing the exercise of the right to education and hindering areas of integration and development social, either in terms of peer relationships, family relationships and work projections, accentuating processes of social exclusion and violation of rights (SENAME, 2017).

In relation, this study has confirmed the relevance of understanding pedagogical intervention practices from the perspective of educational interactions between teachers and children and adolescents assigned to the Specialized Protection Programs in Educational Reintegration in two communes of the country, by observing of intervention practices from its configuration as a scene of human relations and to deepen around this professional action as a critical element, constitutive of the effectiveness in school reintegration. The above constitutes an epistemic and understanding contribution to the phenomenon of school reintegration from interaction, in addition to contributing to the field of studies from the knowledge and meanings of the actors involved in relation to their practices in educational settings, establishing itself as a point of analysis and discussion about its impact on school reintegration and student learning.

\section{References}

ECLAC. (2010). chap. 2. Education in the face of the reproduction of inequality and exclusion: Situation and challenges in Latin America. In Social Panorama in Latin America. United Nations.

Colomina, R., Mayordomo, R., Onrubia, J. (2001). The analysis of discursive activity in educational interaction. Some theoretical and methodological options. Childhood and learning.

Erickson, K.; and Simon, H. (1993) Protocol analysis: Verbal reports as data. Cambridge, MA: MIT. Press.

Glaser, B. and Strauss, A. (1967). The discovery of Grounded Theory. Chicago: Aldine.

Gumperz, J. (1982). Discourse strategies. Cambridge: England.

Hernández, R., Fernández, C. \& Baptista, P. (2010). Investigation methodology. Mexico: McGraw-Hill. (5th ed.). Retrieved from http://soptecc.perujar.com/metodo/inicio.html

Jeong, A. (2005). A Guide to Analyzing Message - Response Sequences and Group Interaction Patterns in Computer mediated Communication. Distance Education. 26 (3), 367-383.

Law 19.876. (2003). Constitutional reform that establishes the compulsory and gratuitous nature of secondary education. Ministry of Education. Library of the National Congress of Chile. Recovered from: https://www.leychile.cl/Navegar?idNorma=210495

MEASURES UC. (2016). Characterization Study of the Educational Reintegration Programs of Sename and Mineduc. Recommendations for public policy and good territorial practices.

Mercer, N., Wegerif, R. and Dawes L. (1999). Children's talk and the development of reasoning in the classroom. British Educational Research Journal, Vol 25, No. 1, 95-111.

Ministry of Education, Division of General Education (2013). Educational Mainstreaming Unit. Chili.

Nasta, L. (s.f.) Effective communication and interaction with educational scope. (s.p.) Psychotherapy Research: Journal of the Society for Psychotherapy Research, 20 (5), 546-563. doi: 10.1080 / 10503301003641886.

Rizo García, M. (2007). Interaction and communication in educational environments: Theoretical, conceptual and methodological reflections. Revista da Associação Nacional two Programs of Post-Graduação em Comunicação.

Román, M. (2013). Factors associated with school dropout and dropout in Latin America: An overview. Iberoamerican Magazine on Quality, Efficacy and Change in Education.

Sucre, F. (2016) School reintegration for vulnerable youth in Latin America. Inter-American Dialogue, December 2016.

Talis. (2013). TALIS 2013 Results: An International Perspective on Teaching and Learning. Paris: OECD.

SENAME. (2017). specialized protection program for children and adolescents with problematic use of alcohol and / or other drugs (pdc). 24 hour program. Ministry of Justice and Human Rights. Chili.

UNESCO. (2015) A growing number of children and adolescents are out of school. Policy Document 22, informative 31.

UNESCO, UNICEF, Chilean Association of Municipalities. (2012b) Educational Exclusion an Urgent Challenge for Chile. Chili.

Weston, C., \& McAlpine, L. (2002). Parallel transcripts: an innovative approach for capturing the impact reflective teaching on student learning experience. In Annual Meeting of the American Education Research Association. New Orleans, LA. 